\title{
Multicenter studies to shed light on fibromuscular displasia and cervical artery dissection
}

\author{
Adriana Bastos Conforto
}

In this issue of Arquivos de NeuroPsiquiatria, Gervasi and colleagues ${ }^{1}$ report the interesting case of a man diagnosed with ischemic stroke and fibromuscular dysplasia (FMD) in the internal carotid artery. FMD is a segmental, noninflammatory, nonatherosclerotic vasculopathy that affects primarily the carotid and renal arteries, but can also involve the vertebral artery and other territories ${ }^{2}$. At least two vascular beds are involved in up to $28 \%$ of the patients. FMD is a pathological diagnosis, with medial fibroplasia being the most frequent finding, but a classical "beading" radiologic pattern with dilatations and stenoses strongly supports clinical suspicion ${ }^{2,3}$. Other radiological patterns such as long, smooth narrowing have also been described.

FMD is more common in women but can also affect men, as in the presented case. It has been suggested that, even though FMD was previously considered to be rare, it may occur in $4 \%$ of adult women, being asymptomatic in most cases ${ }^{2}$. FMD is associated with a greater prevalence of intracranial aneurysms, as previously reported in this journal ${ }^{4}$, and with a greater risk of arterial dissection. The prevalence of FMD in the general population is not known, as well as mechanisms underlying pathogenesis of this vascular disease, or effective treatment strategies. We expect that the International Registry for Fibromuscular Dysplasia ${ }^{2}$ will be valuable to fill some of the gaps in current knowledge about this condition.

In the case presented by Gervasi and colleagues, some features call our attention: the male gender of the patient, and the final diagnosis of FMD associated with arterial dissection provided by digital subtraction angiography but unrevealed by cervical Doppler ultrasound. The patient did not have headache or cervical pain, often present in cervical carotid artery dissection, nor did he present with Horner's syndrome. The described clinical presentation reinforce the concept that, even though the presence of such symptoms and signs may suggest a diagnosis of dissection, their absence should not be considered exclusion criteria ${ }^{5}$.

Clinical supposition of cervical artery dissection is crucial for diagnosis, that has been facilitated by advances in imaging. Magnetic resonance imaging aiming at identification of a mural haematoma in the dissected artery is strongly recommended ${ }^{5}$. Conventional digital subtraction angiography may show filiform stenosis with slow flow, tapered narrowing (string sign), intimal flap, false lumen or aneurysms in a dissected artery, but may not be required if diagnosis of a mural haematoma can be made less invasively with magnetic resonance imaging 5 . In addition, factors influencing outcome have been enlightened by evaluation of collaterals with transcranial Doppler. In pa-
Correspondence

Adriana B. Conforto

Av. Dr. Enéas de Carvalho

Aguiar 255/5084

05403-000 São Paulo SP - Brasil.

E-mail: abconf@usp.br
ESTUDOS MULTICÊNTRICOS: ESPERANÇAS DE MAIS INFORMAÇÕES SOBRE DISPLASIA FIBROMUSCULAR E DISSECÇÃO ARTERIAL CERVICAL

Livre-Docente do Departamento de Neurologia e Médica Assistente do Grupo de Doenças Cerebrovasculares da Divisão de Clínica Neurológica, HCFMUSP; Pesquisadora, Instituto Israelita de Ensino e Pesquisa Albert Einstein, São Paulo SP, Brazil. 
tients with ischemic stroke and cervical carotid occlusion due to dissection, those with none or only one activated collateral vessel were shown to have worse prognosis than those with at least two activated collateral vessels ${ }^{6}$.

The patient reported by Gervasi and colleagues was treated with anticoagulation, often used in clinical practice to avoid stroke recurrence in patients with arterial dissection despite absence of evidence-based guidelines. It has been estimated that, to detect a $5 \%$ difference in the proportion of patients dead or disabled from 20\% to 15\% in patients with cervical artery dissection treated with either antiplatelet drugs or anticoagulants, 1400 patients would have to be included in each arm of a clinical trial ${ }^{7}$. Recently, higher recurrence rates than previously assumed were reported in an observational study in patients with cervical artery dissections, along with higher rates of recurrence in patients treated with antiplatelets compared with those treated with anticoagulants ${ }^{8}$. These findings highlight the need of a clinical trial, despite barriers of funding and difficulties in recruitment. At the moment, feasibility of such a trial is evaluated by the Cervical Artery Dissection in Stroke Study (CADISS) that randomizes patients to either anticoagulation or antiplatelet treatment (http://www.dissection.co.uk).

As take-home messages from the case reported by
Gervasi, we must keep in mind that FMD can occur in men, that cervical Doppler may not be able to diagnose FMD or arterial dissection, and that cervical carotid dissection can occur in the absence of headache, neck pain, or Horner's syndrome. Multicenter studies are key to answer a number of questions that challenge clinical practice in Neurology. Understanding causes and defining the best therapeutic approaches for FMD and arterial dissection remain puzzles to be solved, but there is hope on the horizon.

\section{REFERENCES}

1. Gervasi G, Bramanti P, Calabrò RS. Fibromuscular dysplasia as a rare cause of severe ischemic stroke in a young man. Arq Neuropsiquiatr 2011;69: 404-405

2. Olin JW, Sealove BA. Diagnosis, management, and future developments of fibromuscular dysplasia. J Vasc Surg 2001;53:826-836.

3. Begelman SM, Olin JW. Fibromuscular dysplasia. Curr Opin Rheumatol 2000;12: 41-47.

4. Conforto AB, Puglia Jr P, Yamamoto FI, Scaff M. Progressive cervicocranial arteriopathy with dilatations and stenoses. Arq Neuropsiquiatr 2004;62: 899-902.

5. Debette S, Leys d. Cervical-artery dissections: predisposing factors, diagnosis, and outcome. Lancet Neurol 2009;8:668-678.

6. Silvestrini M, Altamura C, Cerqua R, et al. Early activation of intracranial collateral vessels influence the outcome of spontaneous internal artery dissection. Stroke 2011;42:139-143.

7. Engelter ST, Brandt T, Debette $\mathrm{S}$, et al. Antiplatelets versus anticoagulation in cervical artery dissection. Stroke 2007;38:2605-2611.

8. Weimar C, Kraywinkel K, Hagemeister C, et al. Recurrent stroke after cervical artery dissection. J Neurol Neurosurg Psychiatry 2010;81:869-873. 